\title{
EDUCAÇÃO PARA CONSCIÊNCIA HISTÓRICA NO SISTEMA PRISIONAL
}

\author{
Eduardo Teixeira Gomes ${ }^{1}$
}

Pós-graduação Lato Sensu em Proeja, Instituto Federal do Espírito Santo E-mail: aprendiz.edu@uol.com.br

\begin{abstract}
RESUMO
A singularidade do sistema prisional e a pluralidade dos sujeitos detentos fazem com que a educação prisional deixe de ser pensada apenas como um benefício e seja vista como a razão de ser do sistema prisional. A prisão existe para punir e segregar, entretanto pode tornar-se um projeto de reconstrução de releituras e perspectivas. É o que aponta a visão de Rüsen sobre a consciência histórica: um viés pródigo para novos paradigmas atitudinais. Outro ativo fundamental para nossa análise foi a filosofia de Arendt sobre o poder de pensar e perdoar para reconstruir identidades sob responsabilidades compartilhadas. Trata-se de um trabalho contínuo que abarca Estado e sociedade civil sem uma receita generalizante. Voltada à consciência histórica, a pesquisa foi efetuada com viés bibliográfico e de cunho qualitativo e objetivou pensar princípios epistemológicos que respeitem a formação humana integral - no bojo dos princípios e conceitos em Educação Profissional Técnica Integrada a Educação Básica na Modalidade de Educação de Jovens e Adultos -Formação inicial e continuada - Proeja-FIC. Constatou-se que a prisão, cruelmente, obsta uma recidadania emancipatória através das celas superlotadas, do ensino descontínuo e atropelado pelas lógicas da segurança, da falta de preparo docente específico para o sistema prisional, entre outros fatores. É notório que a violação cotidiana dos direitos educativos dos encarcerados violenta a sociedade brasileira, logo clama-se por uma revolução paradigmática: a formação de uma educação na prisão ao invés de uma educação estigmatizada para prisioneiros.
\end{abstract}

Palavras-chave: Educação, Educação de adultos. Prisioneiros. Educação e Consciência histórica.

\section{INTRODUÇÃO}

Este trabalho é um recorte da monografia apresentada ao Programa de Pós-Graduação em Educação Profissional Técnica Integrada a Educação Básica na Modalidade de Educação de Jovens e Adultos (Proeja) do Instituto Federal do Espírito Santo Campus Serra e fundamenta-se em pesquisas bibliográficas que buscam pensar novos paradigmas para a educação prisional. A grave crise social decorrente da cultura criminal, já enraizada em milhares de adolescentes e jovens, afeta toda a sociedade e precisa ser combatida com uma revolução educacional também no âmbito das prisões, algo que denominamos "Consciência histórica altruísta" a partir da educação no ambiente prisional.

Com o viés bibliográfico dado à pesquisa, enfatizaremos três fontes proeminentes como dados fundamentais à elaboração deste trabalho, a saber: a importância da educação integral no ambiente prisional, destacando os princípios e conceitos do Proeja/FIC ${ }^{2}$, concatenando-os com os desafios do cenário prisional brasileiro; o desvelar do papel das representações sociais na formação dos sujeitos históricos e seus processos culturais à luz de pensadores como Bourdieu, Cardoso, Moscovici, entre outros; e uma análise dos pressupostos formativos para a consciência histórica sob os paradigmas de

\footnotetext{
${ }^{1}$ Especialista em Educação Profissional na modalidade EJA (PROEJA). Educador e Mestre em História Social das Relações Políticas (UFES).

${ }^{2}$ Trata-se do Programa Nacional de Integração da Educação Profissional com a Educação Básica na Modalidade de Educação de Jovens e Adultos, na formação inicial e continuada integrada com o ensino fundamental, doravante chamado de PROEJA /FIC.
} 
Jorn Rüsen (2001), examinando as obras History (2008) e Razão histórica (2001), relacionando-as com perspectivas de Hannah Arendt (2009) em sua obra A condição humana (2009). Essa explicita elementos fulcrais para mitigar a violência e a banalização do mal através das reflexões sobre o poder e a ação.

Rüsen $(2008 ; 2001)$ busca compreender como se articula a estrutura do conhecimento histórico para entender o tempo presente e antecipar um futuro pacificador. Na filosofia de Arendt (2009) emerge o poder de pensar/perdoar como ativo primordial na reconstrução de identidades, sobretudo nas responsabilidades compartilhadas.

A Declaração Universal dos Direitos Humanos preconiza o direito à educação para pessoas encarceradas como um direito inalienável. Seu artigo 26 adquire contornos jurídicos - e obrigatórios - para os Estados consignatários do Pacto Internacional dos Direitos Econômicos, Sociais e Culturais $(\mathrm{PIDESC})^{1}$, dentre os quais está o Brasil. O direito à educação merece uma atenção especial, pois se situa como fator gerador aos demais direitos humanos e potencial garantia de todos os outros. É um direito prioritário, porque é o mais fundamental para a vida humana com dignidade, liberdade, igualdade e criatividade (MONTEIRO, 1999).

Os atuais paradigmas educacionais no sistema prisional logram êxito em ressocializar o egresso? Quais são os paradigmas socioeducativos a serem engendrados para uma educação eficaz na formação do cidadão solidário e consciente de seu papel social? É interessante distinguir educação e direito à educação. A educação é fundamentalmente uma forma de poder que potencializa virtudes e pessoas. O direito à educação é muito mais do que um direito à sala de aula. É um direito proeminente à maior qualidade de vida. A singularidade do sistema prisional e a pluralidade dos sujeitos detentos reivindica uma educação prisional que deixe de ser pensada apenas como um benefício e seja vista como a razão de ser do sistema prisional

Defende-se nesse trabalho uma revolução paradigmática que engendra a proeminência da educação integral na prisão, pois entende-se que uma educação estigmatizada para prisioneiros não é a mais adequada. A perene necessidade de se construir uma justiça social menos assimétrica posiciona os apenados no bojo de um desenvolvimento estratégico para inclusão social (disseminadora da nãoviolência). A situação é de emergência social. De acordo com o Sistema integrado de Informações Penitenciárias (INFOPEN, 2009), a ocupação da mão-de-obra do preso é desprezível, seja pelo trabalho (26\%), seja pelo estudo (17\%). Sobretudo, constata-se que o encarceramento é um adereço à exclusão da educação formal: $67 \%$ dos detentos não concluíram o Ensino Fundamental e apenas $10 \%$ dos detentos (no caso do Estado do Espírito Santo são quase 18\%) têm acesso à educação, em que se incluem atividades diversas, alfabetização, ensino formal e não-formal e cursos técnicos.

Não se tem no país, uma normativa que regulamente a educação formal no sistema prisional. O que se vê são ações isoladas e descentralizadas que dão margem para dificuldades de certificação, continuidade de estudos e a consolidação de uma educação integral normatizada nacionalmente. Mas o que vem a ser uma educação integral? Bem, entende-se por educação integral a educação como uma totalidade social, isto é, que contempla as múltiplas mediações históricas (sociais, econômicas, culturais e políticas) nos processos educativos, sem perder valores humanistas como parte indissociável da educação profissional. Suplanta-se a visão de um ser humano fragmentado e prioriza-se uma formação ética que tem como sombra a formação técnica.

A Lei de Execuções Penais, de 1984, prevê o ensino fundamental obrigatório e profissionalizante ${ }^{2}$. A realidade da população encarcerada, com todas as tragédias que compõem seu cotidiano, faz com que a educação para consciência histórica, no formato da Educação de Jovens e Adultos - EJA, seja

\footnotetext{
${ }^{1}$ O Pacto Internacional sobre Direitos Econômicos, Sociais e Culturais - PIDESC, adotado pela Assembleia Geral da ONU em 1966 é o principal instrumento internacional de proteção dos Direitos Econômicos, Sociais e Culturais. Possui 146 signatários, incluindo o Brasil.

${ }^{2}$ No entanto, a Lei de Diretrizes e Bases para a Educação Nacional (LDB) de 1996 não faz menção específica à educação de adultos presos. O texto final do Plano Nacional de Educação - Lei 10. 172 de 2001 - define como objetivos e metas "implantar, em todas as unidades prisionais e nos estabelecimentos que atendam adolescentes e jovens infratores, programas de educação de jovens e adultos de nível fundamental e médio, assim como de formação profissional (BRASIL, 2001).
} 
fundamental para desenvolver a cultura da não-violência, alçando o egresso ${ }^{3}$ ao patamar de protagonista da ética colaborativa e engendrando perspectivas capazes de revolucionar seu mundo, seu tempo histórico e suas possibilidades futuras. A prática docente na prisão é um diálogo de realidades que pode transformar celas de aula em celas de partos, capazes de trazer à luz vivências cooperativas de que nossa sociedade tanto carece.

Se o caminho do conhecimento é calcado na soma das verdades imperfeitas com a nossa capacidade de transformá-las, então estimular a pensar uma nova história pessoal e coletiva é desafiar a tecer representações sociais para a ética colaboracionista, escrevendo um futuro melhor e utilizando o passado que se domina à luz do presente (RÜSEN, 2001).

\section{SUPLANTANDO ESTEREÓTIPOS ALIJANTES ATRAVÉS DA EDUCAÇÃO INTEGRAL: SOCIEDADE CIVIL E ESTADO EM RESPONSABILIDADE COMPARTILHADA}

\section{Olhares culturais sobre o documento base do Proeja/FIC}

A educação de caráter emancipatório e criativo é incompatível com a lógica da segurança que o ambiente prisional preconiza? Seguramente, não. Apesar de ser estranha ao ambiente prisional (sob a égide da dualidade segurança/liberdade), a educação nos sistemas prisionais é uma das mais importantes políticas públicas, pois refunda identidades e aprendizagens que auxiliam a materializar princípios democráticos e dão ênfase à vida humana. Não pode ser apenas uma moeda de troca entre gestores/agentes prisionais e internos. Do lado dos apenados, olha-se a debilitada educação prisional muito menos como um instrumento transformador de suas realidades do que como um mero trampolim para redução de pena.

É importante, destarte, desenvolver o Proeja/FIC no ambiente prisional para reduzir os efeitos deletérios da perda de liberdade e potencializar reconstruções profissionais com novas oportunidades para inserção social ${ }^{4}$. O Proeja/FIC tem seus alicerces na convergência de três campos da Educação: "a formação para atuação no mundo do trabalho (EPT); o modo próprio de fazer a educação, considerando as especificidades dos sujeitos jovens e adultos (EJA); e a formação para cidadania (Educação Básica)" (BRASIL, 2007, p. 27).

Não obstante, a presença da sociedade civil no projeto político pedagógico e curricular para Educação Prisional é fundamental para exercer o controle social sobre a ação repressora do Estado, bem como para sensibilizar outros setores da própria sociedade sobre os diretos educativos das pessoas encarceradas. A interação entre prisão e sociedade é fundamental para mitigar uma violenta barreira que separa a sociedade de seus próprios problemas e conflitos (BARATTA, 1990, p. 145).

A Sociedade e o Estado precisam trabalhar com responsabilidade compartilhada, sob a égide da intersetorialidade (identificação coletiva, decisão integrada e desenvolvimento colaborativo das políticas engendradas). A participação social formula o controle das políticas públicas, zelando e fiscalizando os projetos e direitos garantidos. A educação de adultos, dentro desse contexto, torna-se mais que um direito: é uma das chaves para o combate à violência no século XXI. Ela é consequência do exercício da cidadania e condição para uma plena participação na sociedade.

O documento base do Proeja/FIC conceitua o jovem e o adulto como trabalhador e cidadão; Além disso, elenca o trabalho como princípio socioeducativo e busca diagnosticar as demandas técnicas, intelectuais e morais na formação do trabalhador para estabelecer uma relação interdependente entre currículo, trabalho e sociedade na formação do indivíduo. Seus principais princípios são:

\footnotetext{
${ }^{3}$ De acordo com a Lei de Execução Penal n.o 7.210, art. 26: "Considera-se egresso: I - o liberado definitivo, pelo prazo de 1 (um) ano a contar da saída do estabelecimento; II - o liberado condicional, durante o período de prova."

${ }^{4}$ A educação integral é explicitada como política educacional tanto na Constituição de 1988 como na Lei de Diretrizes Básicas para Educação de 1996.
} 

a) Princípio da aprendizagem e de conhecimento significativo;
b) Princípio de respeito ao ser e aos saberes dos educandos;
c) Princípio da vinculação entre educação e trabalho: integração entre a Educação Básica e a Profissional e Tecnológica;
d) Princípio da interdisciplinaridade e da avaliação como processo.

Diante dos princípios enunciados é fundamental que a educação nas prisões se integre a um sistema nacional de educação prisional, e este deve estar acoplado a um sistema nacional de educação que garanta o acesso, o desenvolvimento, a permanência e a conclusão dos diversos níveis de estudos, objetivando qualificação ética e profissional. Um direito para todos.

\section{Um olhar sobre a educação no sistema prisional brasileiro}

Percebe-se que $o$ isolamento, a repressão, o descontinuamento e o ambiente hostil obstam a educação eficaz no ambiente prisional. A violação cotidiana dos direitos educativos dos encarcerados protagoniza uma violência contra a sociedade brasileira que financia um sistema destruidor de seres humanos e catalisador de criminalidades. Precisamos de uma prisão cujo eixo existencial seja educar para a vida altruísta. Enfim, muitos são os obstáculos, mas maior é a certeza de que a regeneração não é um milagre impossível.

Mas como garantir o direito à educação no ambiente prisional onde há raros espaços para o exercício de individualidades e da liberdade? Se a educação contribui para a emancipação do ser humano e para o desenvolvimento de potencialidades como as reflexivas, autonomistas e solidárias, então sabotá-la é minar a própria humanização. É urgente reestruturar os modelos atuais de encarceramento para que os preceitos da educação sejam efetivados. Sem dúvida a escola não pode muito, mas pode mais do que pensa que pode.

A esperança emerge quando se inspira possibilidades através do protagonismo do sujeito, pois a "realidade não é algo dado, mas uma construção que o homem faz com o material dado" (ORTEGA, 1989 , p. 26). Apesar do ambiente inóspito da prisão, as práticas educativas identificam caminhos para analisar e remover os obstáculos em busca de uma educação cidadã, rompendo desigualdades sociais naturalizadas (CURY, 2002, p. 247).

O sistema penitenciário brasileiro atravessa uma crise crônica em decorrência de um desaguadouro de fatores que permeiam a história de nosso país: superpopulação carcerária, péssimas condições de higiene, falta de políticas públicas eficazes, fortalecimento do crime organizado, falta de agentes penitenciários especializados, corrupção e também "a inexistências de garantias mínimas aos condenados e o desrespeito institucional à legislação ordinária e aos princípios dos direitos humanos" (ROLIM, 2003, p. 4). A falência da instituição carcerária é somente a ponta do iceberg (DOTTI, 1998, p. 117), pois a pluralidade de fatores conducentes à crise faz com que o assunto perpasse a política, a sociedade e a educação do povo brasileiro.

A prisão não forma, ou recupera, cidadãos. Antes, desperta o que há de pior nos seres humanos em efeito cascata. O cárcere dos apenados, sem uma educação cidadã, formata um turbilhão de insegurança, pois agudiza mais criminalidade e revolta. Desde a antiguidade mesopotâmica a prisão segrega, estigmatiza e decompõe muitos componentes da humanidade. Perversa (MORAES, 2005, p. 255), ela expressa uma falsa segurança à sociedade, pois ali a violência está relacionada ao exercício do poder, como denuncia Foucault (1977, p. 234). As prisões não diminuem a taxa de criminalidade, antes a multiplica. Na prisão se materializa uma insidiosa despersonalização do sujeito que estimula a reincidência criminal em função do aniquilamento, do niilismo, da degradação e banalização do mal. Além do indivíduo, a prisão degenera a família e a sociedade, multiplicando a criminalidade. É uma escola celerada da periculosidade mantida pelo Estado contra a sociedade. Como $60 \%$ da população carcerária é formada por jovens entre 18 e 24 anos de idade (INFOPEN, 2009), a remição 
por estudos é um fator importante a ser considerado, desde que vinculada a etapas educacionais aglutinadas ao desempenho atitudinal.

[...] a ideia de uma reclusão penal é explicitamente criticada por muitos reformadores. Porque é incapaz de responder à especificidade dos crimes. Porque é desprovida de efeitos sobre o público. Porque é inútil à sociedade, nociva e cara. Mantém os condenados na ociosidade, multiplica-lhe os vícios [...] (FOUCAULT, 1977, p. 102).

O desafio é suplantar o caótico ${ }^{5}$ ensino prisional para formar uma consciência histórica solidária que inculque valores fraternos para um futuro compromissado com o respeito e a tolerância. Ora, a sociedade não é aquilo que pesa sobre os indivíduos, mas aquilo que se veicula entre eles. Ela somente pode ser compreendida a partir das vivências, representações e fins subjetivos do indivíduo - isto é, a partir do sentido -, uma vez que o curso exterior é demasiado polimorfo (WEBER, 1999).

\section{REPRESENTAÇÕES SOCIAIS E O SUJEITO DETENTO: PARADIGMAS PARA UMA CONSCIÊNCIA HISTÓRICA}

\section{Representações sociais}

A orientação da vida através da estrutura do tempo, das práticas humanas e dos desafios sociais traz novos insignes para o papel do conhecimento histórico na vida prática. Fazer história é concatenar vida e aprendizagem; cotidiano e saber histórico. As aprendizagens em história norteiam um processo intencional e organizado de formação de identidade que rememora o passado para antecipar o futuro à luz do presente.

É o processo fundamental de socialização e individualização humana que forma o núcleo de todas estas operações. A questão básica é como o passado é experimentado e interpretado de modo a compreender o presente e antecipar o futuro. [...] Teoricamente, a didática da história tem de conceituar consciência histórica como uma estrutura e processo de aprendizado. Aqui é necessário reformular ideias sobre consciência histórica como sendo um fator básico na formação da identidade humana relacionando estes conceitos com o processo educacional, que também é básico para o desenvolvimento humano (RÜSEN, 2006, p.15).

Entende-se o mundo a partir da forma como se vive nele. Destarte, as representações sociais são fundamentais na construção da consciência histórica. Seus fundamentos ocupam uma posição cada vez mais crucial nas relações sociais, principalmente no âmbito socioeducativo que permeia o sistema prisional. Elas são produzidas pelas interações e comunicações discursivas no interior dos grupos sociais. Nesse sentido, a noção de representação social nos remete a "[...] um conjunto de conceitos, afirmações e explicações originadas no cotidiano, no curso das comunicações interindividuais" (MOSCOVICl, 1976).

A representação social é, portanto, a mediação da realidade ou do conhecimento dela. Ela age como uma força reguladora da vida coletiva, definindo lugares e hierarquias, direitos e deveres, valores e

\footnotetext{
${ }^{5}$ Falta de recursos pedagógicos, de preparo docente específico, de profissionais, de material didático inadequado, além das péssimas condições estruturais para funcionamento escolar, resistência de agentes e direções prisionais, entre outros problemas.
} 
símbolos. São veículos importantes para naturalização dos signos nos indivíduos e na sociedade (BOURDIEU, 1996) que desempenham um papel crucial no ajuste prático do sujeito à sociedade.

As representações formulam três tipos de relação com o mundo social: a) classificam e decompõem os padrões intelectuais a partir dos quais a realidade é construída; b) estabelecem práticas que visam fazer reconhecida uma identidade social; c) institucionalizam formas objetivas por meio das quais se marca a existência de forma visível (CHARTIER, 1990). O sujeito que se vê como um "bandido", um excluído, um incapaz, um caso perdido abdica da aquisição de novos capitais culturais por acreditar que jamais os terá. Tal desencanto cultiva mais violência sob a égide da cultura da criminalidade. Quando o sujeito interioriza tais discursos está fundamentando um habitus que não é um mero signo expressando um sentimento, mas, antes, constitui-se o próprio sentimento (BOURDIEU, 1996).

Cada família transmite a seus filhos, mais por vias indiretas que diretas, um certo capital cultural e um certo ethos - sistema de valores implícitos e profundamente interiorizados, que contribuem para definir as atitudes face ao capital cultural e à instituição escolar (BOURDIEU, 1998). Ferro (1989) lembra-nos que "a imagem que temos de outros povos, e até de nós mesmos, está associada à história tal como se nos contou quando éramos crianças. Ela deixa sua marca em nós para toda a existência".

A instituição ensino/escola muitas vezes dissimula - por trás de sua aparente neutralidade - a reprodução das relações sociais e de poder vigentes. Todavia, pode constituir-se como um importante espaço contra-hegemônico (GRAMSCI, 1991). É possível criar saídas para o legado excludente (WEISZ, 2003) através da formação da consciência histórica, em que se preconiza uma percepção do presente que se enraíza no passado e articula projeções no cotidiano.

Punir ou reabilitar? É possível punir e ressocializar? Constituinte do âmbito prisional, o punir e o reabilitar compõem o cerne do dilema na educação prisional. $O$ aumento da criminalidade faz os nossos desafios enormes e complexos, tal como os sujeitos encarcerados e suas complexidades. A dimensão das contradições no cotidiano prisional é exorbitante em dois eixos: a congruência dos objetivos da pena e da prisão com os objetivos socioeducativos em um ambiente aprisionante. 0 pensamento é o viés da ação (ARENDT, 2009, p. 15).

\begin{abstract}
A prática social se põe, portanto, como o ponto de partida e o ponto de chegada da prática educativa. Daí decorre um método pedagógico que parte da prática social onde professor e aluno se encontram igualmente inseridos, ocupando, porém, posições distintas, condição para que travem uma relação fecunda na compreensão e encaminhamento da solução dos problemas postos pela prática social, cabendo aos momentos intermediários do método identificar as questões suscitadas pela prática social (problematização), dispor os instrumentos teóricos e práticos para a sua compreensão e solução (instrumentação) e viabilizar sua incorporação como elementos integrantes da própria vida dos alunos (catarse) (SAVIANI, 2010).
\end{abstract}

\title{
Formação da consciência histórica em Rüsen: perspectivas para emancipação colaboracionista.
}

A história é uma obra humana, portanto não linear e dinâmica. É um espiral acidentado cuja síntese escapa ao controle dos seus agentes. O educar é um método de outorgar contornos ao espiral através da manipulação do passado para projeção do futuro à luz do presente. Se educar já é um desafio em ambientes relativamente normais, imagine no ambiente prisional. O paradoxal processo de ensino e aprendizagem em sistemas carcerários é um fenômeno histórico singular eivado de especificidades desafiadoras, fazendo o detento pensar em si mesmo acima da cultura da criminalidade tecendo mediações históricas e simbólicas que regem novos caminhos (VYGOTSKY, 2003). 
Jörn Rüsen (2001) elenca a racionalidade como fundamento estratégico para se pensar historicamente, pois o agir humano é sempre intencional. Todo pensamento histórico se exprime sob a forma de uma argumentação que ordena as subjetividades e as concatena com outras formas de conhecimento. Assim, a consciência histórica pode ser definida como a soma das operações mentais com as quais "os homens interpretam sua experiência da evolução temporal de seu mundo e de si mesmos, de tal forma que possam orientar, intencionalmente, sua vida prática no tempo" (RÜSEN, 2001 , p. 57). Ela tem um papel fulcral nas tomadas de decisão, pois não se resume ao conhecimento do passado, mas, sobretudo, trata-se de uma maneira de pensar.

A consciência histórica dá estrutura ao conhecimento histórico como um meio de entender o tempo presente e antecipar o futuro. Ela apresenta uma combinação complexa que contém a apreensão do passado regulado pela necessidade de entender o presente e de presumir o futuro. Se os historiadores vierem a perceber a conexão essencial entre as três dimensões do tempo na estrutura da consciência histórica, eles podem evitar o preconceito acadêmico amplamente aceito de que a história lida unicamente com o passado: não há nada a se fazer com os problemas do presente e ainda menos com os do futuro (RÜSEN, 2006, p. 14).

É crucial suplantar injustiças através de uma educação humanitária e não autoritária, que propicie os elementos de uma aprendizagem contínua e individualizada que os nossos tempos exigem (KOICHIRO, 2002). A premissa fundamental é forjar o sujeito reflexivo, isto é, aquele que pensa a partir da prática real com o que pode e deve ser feito.

Em ambientes tensos e cruéis como a prisão, a necessidade de se projetar um futuro pacificador é ainda maior. Não um futuro distante, mas uma "ainda-não" próximo da realidade do sujeito (SANTOS, 2008) $)^{6}$. Além de projetar um futuro com o passado que domino, Rüsen explicita que a consciência histórica pressupõe o indivíduo existindo em grupo, tomando-se como referência os demais, de modo que a percepção e a significação do tempo só podem ser coletivas. De acordo com Rüsen (2008) as etapas do desenvolvimento da consciência histórica podem ser distinguidas a partir de quatro formas básicas: a afirmação, a continuação, a negação e a transformação. Essas formas de argumentação empreendem quatro níveis gradativos - tradicional, exemplar ${ }^{7}$, crítico $^{8}$ e genético ${ }^{9}$.

A consciência histórica baseia-se na circunstância de que as experiências do tempo presente só podem ser interpretadas como experiências, e o futuro apropriado como perspectiva de ação. A consciência histórica é o trabalho intelectual realizado pelo homem para tornar suas intenções de agir conformes com a experiência do tempo. [...] Trata-se de um processo da consciência em que as experiências do tempo são interpretadas com relação às intenções de agir e, enquanto interpretadas, inserem-se na determinação do sentido do mundo e na auto-interpretação do homem, parâmetros de sua orientação no agir e no sofrer (RÜSEN, 2001, p. 59,63).

\footnotetext{
6 "O Ainda-Não é uma categoria que exprime o que existe apenas como uma tendência, um movimento latente no processo de se manifestar. O Ainda-Não é o modo como o futuro se inscreve no presente e o dilata. Não é um futuro indeterminado nem infinito, mas uma consciência antecipatória. [...] Objetivamente, o Ainda-Não é, por um lado, capacidade (potência) e por outro, possibilidade (potencialidade). [...] O Ainda-Não inscreve no presente uma possibilidade incerta, mas nunca neutra; pode ser a possibilidade da utopia ou da salvação, mas também a possibilidade do desastre ou perdição!" (SANTOS, 2008, p. 116,117).

${ }^{7} \mathrm{O}$ exemplo pressupõe a experiência do passado personificando regras gerais de mudança temporal e conduta humana.

8 Neste tipo estimula-se a crítica para romper a continuidade dominante e construir identidades a partir de estratégias contrahegemônicas. Confrontam-se valores morais com a evidência histórica de suas origens, além de questionar as legitimidades do status quo.

${ }^{9}$ Aceita que a história faz parte do passado, mas aponta um novo futuro. Abarca diferentes pontos de vista que integram o entendimento de mudança temporal.
} 


\title{
QUATRO PRESSUPOSTOS DO PENSAMENTO EMANCIPATÓRIO SOB A ÉGIDE DA VIOLÊNCIA CARCERÁRIA: UM OLHAR DE HANNAH ARENDT.
}

Ser humano é ter muito diante de si, pois a possibilidade do pensar e agir movimenta o mundo dos homens. O projeto de ressocialização é um projeto de reconstrução de perspectivas - e instrumentos - de sobrevivência acima dos fatores conducentes ao crime.

O caráter profissionalizante da educação é, portanto, o viés de uma nova condição humana, tendo o trabalho como princípio e método, enquanto o pensamento é o catalisador de perspectivas transformadoras. Concomitante à proposta de consciência histórica de Rüsen, o pensamento de Arendt é indissociável da experiência pessoal dos sujeitos. Para ela, não pode haver um processo de pensamento que não seja o resultado de uma experiência pessoal. Isto é, todo o pensamento é um repensar em função de algo externo. As condições humanas variam de acordo com o lugar e o momento histórico do qual o homem é condicionante e condicionado (ARENDT, 2001).

O acesso à educação emancipatória potencializa humanidades e reduz a assimetria social, cooperando com o desenvolvimento do potencial conciliador e altruísta através de ações educativas voltadas a valores como tolerância, coletividade, justiça, altruísmo, solidariedade e responsabilidade compartilhada.

É fundamental recriar significados para a vida em sociedade, potencializando experiências colaboracionistas. Arendt ressalta que não é pelo labor ou pelo trabalho ${ }^{10}$ que o homem se realiza no mundo, ou se dignifica, mas sim pelas suas "palavras e atos" (ARENDT, 2009 [1958], p. 18).

\begin{abstract}
A liberação da necessidade (do trabalho) não se confunde com liberdade, pois a liberdade exige um espaço próprio que é o espaço da ação e da palavra [...] liberdade não é, portanto, a concepção moderna e privada da não interferência do isolamento ou da privacidade, mas liberdade se constitui, sobretudo, publicamente dentro de um espaço plural, igual enquanto direito e democrático. (ARENDT, 2009 [1958], p. 18).
\end{abstract}

As palavras e atos com consciência histórica na justiça social podem criar perspectivas humanas colaborativas apesar do capitalismo predatório que nos cerca. É notória a correlação entre a exclusão do trabalho e o aumento da criminalidade/violência. Com uma excepcional sensibilidade para contradições entre o ideal ilustrado da modernidade e as adscrições políticas primordiais, a autora externa quatro pressupostos fundamentais para a questão da violência: a experiência pessoal, a compreensão politicossocial; o desenraizamento e a junção entre liberdade e pluralidade compartilhada.

A experiência pessoal engloba todas as demais instâncias e por elas é afetada. Trata-se da arena onde o processo transformador da condição humana se materializa. Emerge na junção entre liberdade individual e o pensamento como percepção de um mundo diverso e compartilhado. Está permeada da ação dos outros em redor, pois todas as atividades humanas estão condicionas pelo fato de os homens viverem juntos (ARENDT, 2009 [1958], p. 31). O sujeito tem no bojo de sua experiência pessoal as chaves - e as celas - de sua existência, pois a força dos modelos culturais dominantes não anula o espaço próprio de sua recepção (CHARTIER, 2009, p. 46).

A condição humana é flexível pois, as condições nas quais a vida foi dada ao homem "[...] interferem em tudo aquilo com o qual ele entra em contato e torna-se imediatamente uma condição da sua existência" (ARENDT, 2009 [1958], p. 17). O objetivo maior é libertar o apenado da vida/condição que

\footnotetext{
10 “O labor é a atividade que corresponde ao processo biológico do corpo humano, cujo crescimento espontâneo, metabolismo e eventual declínio têm a ver com as necessidades vitais produzidas e introduzidas pelo labor no processo da vida. A condição humana do labor é a própria vida. O trabalho é a atividade correspondente ao artificialismo da existência humana, está não necessariamente contido no eterno ciclo vital. [...] A condição humana do trabalho é o valor do mundo e suas convenções!” (ARENDT, 2009 [1958], p.15).
} 
Ihe move à marginalidade. $O$ desenraizamento da cultura criminal conduz à autêntica liberdade. Sem ele o detento não consegue se ver, ou pensar acima da marginalidade.

A prisão é uma extensão da periferia e vice-versa, assim o trabalho socioeducativo para formação da consciência histórica altruísta precisa começar em todas as esferas do Ensino Fundamental e Médio. As questões pertinentes ao caráter são determinantes na formação do indivíduo, uma vez que: "são os traços pessoais a que damos valor em nós mesmos e pelos quais buscamos que os outros nos valorizem" (SENNETT, 2008, p. 10). Capacitar a escola pública como espaço gerador de altruísmo é uma das mais importantes políticas públicas de nossos tempos.

Os processos cognitivos desenvolvem percepções que materializam realidades, assim, sob o engenho das suas próprias mãos, o homem (re)escolhe seu caminho e os percursos dentro deste caminho. Apesar do ambiente prisional incentivar uma banalização do mal, é crucial formatar uma educação prisional contínua capaz de resgatar no encarcerado o encantamento com a cidadania. Na escola o conhecimento torna-se um instrumento para se pensar a si mesmo, as atrocidades sem sentido e projetar um futuro multiplicador da não-violência. O pensamento crítico é um dos pilares para um homem livre, afinal, “[...] uma vida sem pensamentos seria uma vida sem sentido!" (ARENDT, 1992, p. 134).

"Pode o problema do bem e do mal, nossa faculdade de distinguir o certo do errado, estar conectado com nossa faculdade de pensar?" (ARENDT, 1992, p. 6). Na verdade, deveria. A atividade do pensar sugere justamente que diferenças e alteridades, características do mundo das aparências, sejam permanentemente arguidas pela prática do homem (ARENDT, 2009, p. 305). "O pensar pode condicionar uma pessoa contra fazer o mal porque a sua capacidade de julgar é um subproduto da atividade pensante" (ARENDT, 1992).

A banalização do mal e da violência reforça a retórica do crime entre jovens apenados. Naturaliza-se como uma segunda pele de ódio e desencanto, que demarca sua racionalidade. Ora, o homem se realiza - e se distingue - pelas significações racionais e subjetivas (ARENDT, 2009 [1958], p. 97) que norteiam seu trabalho.

A pluralidade humana, condição básica da ação e do discurso, tem o duplo aspecto da igualdade e da diferença. Se não fossem iguais, os homens seriam incapazes de compreender-se entre si e aos seus ancestrais, ou de fazer planos para o futuro ou prever as necessidades das gerações vindouras (ARENDT, 2009 [1958], p. 188).

Podemos classificar o aluno detento em três categorias: dominados ${ }^{11}$ críticos $^{12}$ e desencantados ${ }^{13}$. Apenas o homem pode distinguir-se, expressar-se em formas próprias, e configurar sua vida activa. Assim, o ser humano expressa-se em palavras que geram atos, que por sua vez, demarcam a natureza humana. Além disso, suplanta ambientes socioculturais e seus estigmas, forjando um novo caráter. Nada é impossível ao que crê. A junção das palavras e atos faz eclodir o poder. O detento é - sujeito da vida activa, ele pode criar novos parâmetros de conduta, bem como novas representações de si e do universo ao seu redor.

A capacidade de agir traz em si elevado teor de potencialidade que the permite sobrepujar inaptidões do sujeito e desvios das adversidades corruptoras, propiciando revoluções atitudinais

\footnotetext{
${ }^{11}$ Pessoas encarceradas que não possuem a consciência de sua sujeição enquanto agentes históricos pensantes. Assim, reproduzem suas mazelas sem criar alternativas para romper significativamente as dominações socioculturais.

12 Encarcerados que possuem a consciência de sua sujeição e por isso conseguem produzir um conhecimento crítico capaz de realocar arranjos políticoculturais contra as premissas conducentes de sua criminalidade. Um saber crítico, ainda que sujeitado, é ativo fundamental das revoluções culturais.

${ }^{13}$ Detentos que possuem a consciência de sua sujeição enquanto agentes históricos, mas não desenvolvem essa consciência devido ao desencanto do cotidiano na prisão.
} 
capazes de compartilhar palavras e atos (ARENDT, 2009 [1958], p. 210) com novos sujeitos. O poder delegado da ação é dinâmico e infinito.

Um exemplo é o conceito de perdão. Arendt (2009 [1958], p. 251) acentua que Jesus revolucionou o conceito de perdão, porque o salientou como um poder libertador da culpabilidade. 0 termo grego utilizado foi aphiemi, que significa "enviar para frente", "anular dívida", "remir". O perdão, no sentido jesuítico, é libertar, soltar, remover a ofensa. $O$ fato de Jesus ter pronunciado tais premissas em nível religioso não é motivo para levá-las menos a sério num sentido secular (ARENDT, 2009, p. 250).

O perdão é a profilaxia para os danos entre os homens. Ele engendra uma nova chance para os homens exercerem sua liberdade construtiva, emancipados dos atos destrutivos que os marcaram. Todavia, quem perdoa quem? A necessidade do perdão na condição prisional é dupla: por um lado, os grupos sociais circundantes "perdoam" o egresso na forma da $l \mathrm{ei}^{14}$, abandonando estereótipos excludentes; por outro lado, o egresso perdoa a si mesmo e as conjunturas que marcaram suas fraturas sociais.

\section{CONCLUSÃO}

A prisão é uma fase terminal de um ciclo que teve início, em muitos casos, nos períodos da infância e adolescência, configurando-se assim um processo de construção da cultura criminal. Violência e criminalidade são sinônimos intrínsecamente relacionados. 0 sistema penitenciário precisa de uma grande reforma, porém, antes de construir algo novo, faz-se necessário reconhecer e denunciar os mecanismos que acentuam a banalização do mal.

Como já vimos, a dinâmica natural da instituição prisional tolhe componentes da identidade do sujeito (GOFFMAN, 2005). É preciso traçar planos e metas articulados com todos os segmentos sociais para mitigar a segregação social dos apenados. Políticas públicas bem definidas, profissionais com formação apropriada e uma infraestrutura adequada são imprescindíveis para um processo socioeducacional eficaz, porquanto a educação inadequada concorre para o fracasso do que representa a pena de prisão para a reabilitação de apenados.

Educar em prisões não pode significar uma educação de prisioneiros, mas uma educação integral permanente para todos aqueles que estão ligados ao ambiente prisional. O problema do sistema prisional não está apenas lá, é uma crise que decorre de vários aspectos sociais. Não basta criar leis que garantam o direito do preso à educação, é preciso concentrar políticas públicas, recursos financeiros e estratégias docentes em programas eficazes. Obviamente, a complexidade do meio carcerário, sua natureza multidimensional e suas contradições remetem à impossibilidade de uma receita generalizada.

A ingenuidade acrítica negligencia os problemas múltiplos que cada contexto nos impõe. Portanto, é fundamental discernir as demandas de cada unidade prisional para implementar diferentes estratégias que transcendem os muros das prisões. Saber trabalhar com as contradições e conflitos a exaustão é condição fundamental para o educador que atua em prisões (GADOTTI, 1993, p.43). Algumas são urgentes: políticas públicas intersetoriais com a sociedade civil; inclusão da disciplina 'educação em prisões' na grade dos cursos de pedagogia; a formação de cursos em Pós-Graduação nessa área ${ }^{15}$; a constante citação nos meios de comunicação desta temática, entre outras.

O detento é co-artífice de sua marginalidade, mas também pode ser o protagonista de sua consciência histórica emancipatória. Alguém capaz de compartilhar a premissa de que o alvo principal não é deixar a prisão, mas abandonar as vivências que o conduziram até lá. Assim, romper

\footnotetext{
${ }^{14}$ Uma vez cumprida sua pena o egresso não pode viver sob estigma do crime, pois ele precisa de espaços para provar sua regeneração. Ninguém é irrecuperável, pois todos podem nascer para uma nova vida que decorre das apropriações de valores e virtudes em novas representações sociais que remetem a um distinto sentido histórico de existência.

${ }^{15}$ Ressalta-se que a adequada política de formação de educadores não resolve sozinha a teia de complexidades que permeia o ensino prisional, mas sua ausência compromete significativamente todo o trabalho.
} 
paradigmas violentos propicia ao encarcerado desenvolver práticas solidárias, afetivas, tolerantes e altruístas.

Desde a detenção para adolescentes, a cultura prisional precisa ser urgentemente substituída, em todos os seus níveis, por uma cultural pedagógica. Das delegacias de detenção provisória aos presídios, tudo deve ser reformulado, objetivando uma reeducação emancipatória para a consciência histórica altruísta, o desenvolvimento de potencialidades individuais e o aprimoramento das humanidades solidárias. Todavia, isso é impossível sem que as escolas, famílias e igrejas aprimorem a formação humana, uma vez que o presídio é um espelho das relações sociais vigentes fora de seus muros.

Ninguém é violento em si mesmo, o problema da violência não está no criminoso, antes, está no homem. Os homens aprendem a odiar e a amar, logo, qualquer um pode aprender a viver uma vida abundante de perdão e solidariedade. Diante da galopante cultura criminal dos dias atuais é melhor pensar e agir para se construir comunidades altruístas do que perder mais tempo e energia segregando. A cultura da criminalidade se amplia e diversifica.

É o tempo de conquistarmos novos mundos navegando pelas águas da consciência histórica altruísta. $O$ detento que pensa eticamente transmite a confiança em um mundo melhor, mesmo que a confiança entre os homens seja escassa.

Cada um de nós é um pouco do mundo que deseja ver existir. Sonhar com uma geração de jovens egressos do sistema penal com consciência histórica para protagonizar uma sociedade menos injusta e mais igualitária, é compreender o desafio de mediar legados conflituosos e virtudes latentes para suplantar os inquestionáveis sucessos que a prisão tem obtido na multiplicação da marginalidade. Um outro sistema prisional é possível.

\section{REFERÊNCIAS}

ARENDT, H. A condição Humana. 10 ed. Rio de Janeiro: Forense, 2009.

ARENDT, H. A vida do espírito: o pensar, o querer, o julgar. Rio de Janeiro: Relume Dumará, 1992.

ARENDT, H. Da violência. Brasília: Ed. Universidade de Brasília, 1985.

BRASIL. Congresso Nacional. Constituição Federal da República Federativa do Brasil. 5 de Outubro 1988.

BRASIL. Congresso Nacional. Lei Federal no 9. 394. Lei de Diretrizes e Bases da Educação Nacional. 20 de Dezembro de 1996.

BRASIL. Documento Base: Programa Nacional de integração da Educação Profissional com a Educação Básica na modalidade de educação de jovens e adultos: Formação Inicial Continuada. Brasília. 2007.

BRASIL. Ministério da Justiça. Departamento Penitenciário Nacional. Sistema Penitenciário no Brasil: estatísticas do Departamento Penitenciário. Brasília. 2009.

BRASIL. Ministério da Justiça. Departamento Penitenciário Nacional. Sistema Penitenciário no Brasil: dados consolidados. Brasília. 2006.

CURY, C. R. J. Superando a ideia da educação compensatória. Belo Horizonte: PUC MINAS. 2002.

FERRO, Marc. A História vigiada. São Paulo: Martins Fontes, 1989. 
MORANDI, Franc. Modelos e métodos em Pedagogia. Tradução de Maria Leonor Loureiro. Bauru, S. P: EDUSC, 2002.

NETO, Antonio da Costa. Paradigmas em educação no novo milênio. 2. ed. Goiânia: Kelps, 2003.

BARATTA, A. Por un concepto crítico de reitegración social del condenado. In: Criminologia crítica (Fórum internacional de Criminologia crítica). Belém: CEJUP, 1990.

BOURDIEU, Pierre. A escola conservadora: as desigualdades frente à escola e à cultura. IN: NOGUEIRA, M.; CATANI, A. Escritos de Educação. 8. ed. Petrópolis, RJ: Vozes, 1998.

BOURDIEU, Pierre. A economia das trocas linguísticas. São Paulo: Edusp, 1996.

BRANT, V. C. O trabalho encarcerado. Rio de Janeiro: Forense, 1994.

CARDOSO, C. F.; MALERBA, J. (Org.). Representações: contribuição a um debate transdisciplinar. Campinas, SP: Papirus, 2000.

CHARTIER, Roger. A história cultural: entre práticas e representações. Rio de Janeiro: Bertrand Brasil, 1990.

DOTTI, René. Ariel. Bases e alternativas para o sistema de penas. 2. ed. São Paulo: Revista dos Tribunais, 1998.

DUBET, François. As desigualdades multiplicadas. Ijuí: Ed. Unijuí, 2003.

ELIAS, Nobert. O processo civilizador, Vol 2. Rio de Janeiro: Zahar, 1994.

FAZENDA, I.(Org. ). Metodologia da pesquisa educacional. 7. ed. São Paulo: Cortez, 2001.

FOUCAULT, MICHEL. Vigiar e punir: Petrópolis: Vozes, 1977.

FREIRE, P. Educação como prática da liberdade. 27. ed. Rio de Janeiro: Paz e Terra, 2003.

FREIRE, P. Pedagogia do Oprimido. 41. ed. Rio de Janeiro: Paz e Terra, 2005.

FREITAS, Barbara. Escola, Estado e Sociedade. 6. ed. São Paulo: Marcas, 1986.

GADOTTI, M. Fórum Mundial de Educação: pro-posições para um outro mundo possível. São Paulo: Editora Instituto Paulo Freire. 2009.

GADOTTI, M. \& ROMÃO, José. Educação de Jovens e Adultos: teoria, prática e proposta. 7. ed. São Paulo: Cortez / Inst. Paulo Freire, 2005.

GATTI, B. A. A construção da pesquisa em educação no Brasil. São Paulo: Plano, 2002.

GOFFMAN, E. Manicômios, prisões e conventos. 7. ed. São Paulo: Perspectiva, 2005.

GRAMSCI, A. Os intelectuais e a organização da cultura. 8. ed. Rio de Janeiro: Civilização Brasileira, 1991.

HABERMAS, J. Passado como futuro. Entrevista a Machael Haller. Rio de Janeiro: Tempo Brasileiro, 1993. 
KOICHIRO, M. A UNESCO e os desafios do novo século. Brasília: UNESCO, 2002.

KUPER, Adam. Cultura: a visão dos antropólogos. São Paulo: Edusc, 2002.

JOSEPH, I. Erving Goffman e a microssociologia. Rio de Janeiro: FGV. 2000.

MONTEIRO, Agostinho dos Reis. O direito à educação. Lisboa: Horizonte. 1999.

MORAES, Pedro Rodolfo Bodê de. O sistema penitenciário brasileiro. In: MORAES, Pedro Rodolfo Bodê de. Punição, encarceramento e construção de identidade profissional entre agentes penitenciários. Curitiba: IBCCRIM, 2005. Cap. 8. Parte 2.

MOSCOVICI, S. A Representação Social da Psicanálise. Rio de Janeiro: Zahar, 1976.

RÜSEN, Jörn. History: Narration, Interpretation, Orientation. New York, Oxford: Berghahn Books. 2008.

RÜSEN, Jörn. Didática da história: passado, presente e perspectivas a partir do caso alemão. Praxis Educativa. Ponta Grossa, PR. V. 1, n. 2, p. 7-16, jul - dez, 2006.

RÜSEN, Jörn. Razão histórica. Brasília: Editora da UnB, 2001.

SANTOS, B. S. A gramática do tempo. 2. ed. São Paulo: Cortez. 2008.

SAVIANI, D. Pedagogia histórico-crítica: primeiras aproximações. Campinas: A. Associados, 2000.

THOMPSOM, Augusto F. G. A questão penitenciária. Petrópolis: Vozes, 1976.

WEBER, Max. Economia e Sociedade. Brasília, DF: Editora UnB, 1999. Vol 2.

WEISZ, T. O diálogo entre o ensino e a aprendizagem. São Paulo: Ática. 2003. 
